\title{
Universal design and accessibility: an approach of the influence of muscle strength loss in the risk of falls in the elderly
}

\author{
Reis, P. ${ }^{\mathrm{a}, \mathrm{b}^{*}}$, Moro, A. ${ }^{\mathrm{a}, \mathrm{b}, \mathrm{c}}$ Bins Ely, V. ${ }^{\mathrm{a}}$ Fernandes, C. ${ }^{\mathrm{a}, \mathrm{e}}$ Vilagra, J. ${ }^{\mathrm{d}}$ Peres, L. ${ }^{\mathrm{d}}$ Fogaça Junior, O. ${ }^{\mathrm{f}}$ and Merino, \\ Eugenio $^{\mathrm{a}}$ \\ a Programa de Pós-Graduação em Engenharia de Produção, Universidade Federal de Santa Catarina, SC, Brazil \\ ${ }^{\mathrm{b}}$ Instituto de Ensino Superior de Foz do Iguaçu, Pr, Brazil \\ 'Programa de Pós-Graduação em Educação Física, Universidade Federal de Santa Catarina, SC, Brazil \\ 'Universidade do Oeste do Paraná, Pr, Brazil \\ ${ }^{e}$ Universidade Federal Tecnológica do Paraná, Pr, Brazil \\ ${ }^{f}$ Universidade do Norte do Paraná, Pr, Brazil
}

\begin{abstract}
This study was conducted with older adults living in a long-stay institution in the city of Foz do Iguacu, Parana, Brazil with the objective of assessing the influence of muscle strength loss in the risk of falls. The sample consisted of 65 elderly who walk without the aid of support for locomotion, 37 women and 28 men, aged between 67 and 80 years. The risk of falls was assessed through the TUG test. To determine the handgrip strength, a hand dynamometer model Jamar ${ }^{\circledR}$ was used, which provides the result in $\mathrm{kg} /$ force (kgf), being held only with the dominant hand. The results showed that in the last 12 months, only $32 \%$ of the elderly surveyed had no fall and the average handgrip strength was $24.32 \pm 11.22 \mathrm{kgf} ; 40 \%$ had one fall and the average handgrip strength was $23.82 \pm 10.18 \mathrm{kgf} ; 8 \%$ had two falls and the average handgrip strength was $19.48 \pm$ $8.21 \mathrm{kgf}$ and $20 \%$ had more than one fall and the average handgrip strength of $18.13 \pm 7.33 \mathrm{Kgf}$., indicating that the force levels are statistically lower among elderly at high risk of falls $(\mathrm{p}>0.05)$. It was concluded that the lower the force level, the greater the likelihood of falls. Thus, it is important to stress that due to the loss of muscle strength, all ergonomic hazards and architectural barriers must be removed so that older adults can perform their tasks more easily, with comfort and safety.
\end{abstract}

Keywords: aging; ergonomics; accident

\section{Introduction}

Falls in the elderly are a major challenge for the universal design and accessibility of architectural and urban design of cities, given the difficulty of movement and autonomy at this phase of life [2]. Aging is a natural human process, with significant decrease in functionality; thus, providing this population an ergonomic environment is crucial to maintaining a good quality of life, because older adults have several difficulties in walking, especially in activities at the beginning of the movement, walking backwards, sitting, standing, acyclic movements and uneven grounds [19]. The aging world population is not new phenomenon. China, Japan and other countries in
Europe, and North America, have lived, for some time, with a large contingent of older adults. Among the 11 countries with the largest populations of elderly, eight of them belong to the group of developing countries [46].

The initial drop of mortality rates resulted from various reasons: increased urbanization, improved nutrition, higher levels of personal hygiene and better sanitary conditions both in domestic spaces and at work, development of new diagnostic technologies, therapeutic procedures and medicines, discovery of vaccines, among others. Gradually, the epidemiological profile of the population changed. The consequence was the increase of disabilities and dependence, which led to greater use of health

\footnotetext{
* Corresponding author: Pedro Ferreira Reis - Instituto de Ensino Superior de Foz do Iguaçu, Pr, Brazil - Universidade Federal de Santa Catarina - Programa de Pós Graduação em Engenharia de Produção - Ergonomia - Laboratório de Biomecânica - Campus Universitário, Trindade, Florianópolis, SC, Brasil. CEP: 88.040-970; Tel. (55) 4837218530. E-mail: ergoreis@hotmail.com
} 
services [12]. In Brazil, the number of people with restricted mobility and independence is growing alarmingly. Research indicates that approximately $23 \%$ of the Brazilian population is composed of older people with some kind of disability, whether temporary or permanent [45]. Thus, the presence of uneven surfaces, stairs, elevators, not suitable bathrooms, is considered architectural barriers $[18,19,36]$.

In the performance of any architectural project, ergonomics must be present, since the universal design should be focused on all buildings, so that environments can be accessible to all, with comfort and safety [34]. Thus, all risks that may affect human health should be considered at the time of construction of a building, especially ergonomics, chemical and biological risks [18]. Therefore, the interdisciplinary and multidisciplinary involvement in the development of accessible architectural projects focused on universal design will offer a better understanding of professionals from exact areas [44].

Unfortunately, Brazil still has many unsuitable environments with minimum accessibility, and in this context, correction ergonomics should be the only solution because since about $23 \%$ of the Brazilian population is composed of older adults, and any tool that can assist in the improvement of an environment, whether at work, home and leisure should be used, and oriented sidewalks, questionnaires, discomfort scales, functional tests and observations may contribute to a more humanized environment [22]. These measurements will provide an ergonomic environment, free of architectural barriers and with comprehensive accessibility, with projects based on the universal design principles [2,18]. Thus, providing an ergonomic environment, especially without architectural barriers, will contribute to a healthy aging [40].

Having an accessible environment is not enough. The people involved should have awareness of its usability, as the ergonomic risks can occur not only due to an insecure condition but also due to an unsafe act. Therefore, avoiding ergonomic risks is of fundamental importance to prevent falls among elderly people, and we strongly recommend the following:

- Do not leave obstacles along the way;

- Avoid using carpets;

- Check the floor every day;

- Do not use wax;

- Have adequate lighting;

- Have handrails on stairs;
- Have an accessible bathroom;

- Beware of the garbage along the locomotion areas [18].

The high level of sedentary lifestyle in older adults who live in long-stay institutions leads to a considerable loss in functional mobility, which is aggravated by the absence of family, contributing to a high prevalence of morbidities with suffering and high economic and social costs $[17,46]$. In this sense, it is important to warn designers of the physiological changes arising from the aging process, affecting not only the musculoskeletal system, but also reproduction, audition, vision, movement and balance $[32,42]$. The aging process shows some changes that can be considered normal, which are called senescence, and the changes produced by the numerous diseases that can affect the elderly are part of senility [14].

Providing this population with an ergonomic environment is of fundamental importance for maintaining a good quality of life, since elderly people present several difficulties in walking, mainly in activities at the beginning of the movement, walking backwards, sitting, standing, acyclic movements and uneven surfaces $[13,18,31,41,44]$.

It is important not to let the elderly in environments with risk of falls, since the trauma of a fall contributes to a psychological barrier of the fear of falling, leading to a decline in functionality, with changes in posture, balance and socialization, which may progress to stress and depression [3,28,35].

An easy-to-perform practical test to assess the risk of falls, which can be applied by any professional who works with this population is the TUG test, which assesses the basic functional mobility of the elderly, being carried out by analyzing the time and number of steps used by the elderly at the moment he/she comes up from the chair, walks 3 meters, returns and sits on the chair again, and the more steps and the longer time the elderly needs to make the trip mean an increased risk of falls, and time shorter than 10 seconds means low risk of falls; from 11 to 20 seconds means intermediate risk of falls and more than 20 seconds means high risk of falls [10,37]. This test starts with a verbal stimulus, timing from this verbal stimulus until the elderly returns and sits on the chair [36].

Professionals involved in projects of environments built for the elderly population should observe the functional, biomechanical and anthropometric characteristics of users, significantly contributing to improving the quality of life of this population, because the act of moving around 
without assistance is a factor that contributes to their self-esteem [5,18,24].

At all stages of human life, contact with friends is necessary, which provides physical and mental welfare, factors necessary and important to the human physiological metabolism [15]. In this sense, it is important to emphasize that for an environment to have a good spatial accessibility, it must provide conditions for the subject to come and go with full independence, always acting with comfort and safety [18].

Due to the biological aging, diseases and ergonomic factors influence in the appearance of falls. Unfortunately, in environments designed for the elderly, there are people who treat the problem as normal, linking them to the aging process [17]. Therefore, it is important to verify the history of falls and to detail the location and reason for the occurrence of the fall, whereas this condition will cause the appearance of fractures and fear, being the sixth leading cause of mortality among the elderly [26]. It is important to emphasize that aging is a normal condition of human beings, where there are biochemical, morphological and biological changes, which make the body more vulnerable to situations of the daily life, whether of internal or external source [22].

It is also important stressing that older adults with diseases that affect balance and mobility are more prone to falls. Thus, physical activity programs should be aimed at this population, so that the functional mobility is improved, since current research shows that active seniors have less risk of falls due to the improvement of postural balance arising from the improvement in muscle strength [22].

A good accessibility must have a good orientation, where plates, signs or any kind of information are quite accessible, with good displacement condition, either horizontally and vertically, pointing out stairs, passageway, ramps and elevators, and that communication could be interpersonal or in the man $\mathrm{x}$ machine relationship, without the need for prior training [29,35]. Finally, the user with or without temporary or permanent limitations should be able to come and go in an accessible environment independently, with comfort and safety [9].

\section{Method}

\subsection{Participants}

Given the above, an observational and exploratory study was conducted with older adults living in a long-stay institution in the city of Foz do Iguacu, Parana, Brazil. The sample consisted of 65 elderly who walk without the aid of support for locomotion, 37 women and 28 men, aged between 67 and 80 years.

Permission to participate in the study was obtained through the free and informed consent form (FICF), which was signed individually by the elderly and the head of the institution. The procedures were approved by the local Committee for Ethics in Research with Human Subjects, according to the Declaration of Helsinki.

\subsection{Instruments}

Data collection was conducted through various imaging records (photographs and videotaping) of events related to the physical environment occupied by participants their behaviors and TUG Test (Figure $1)$.
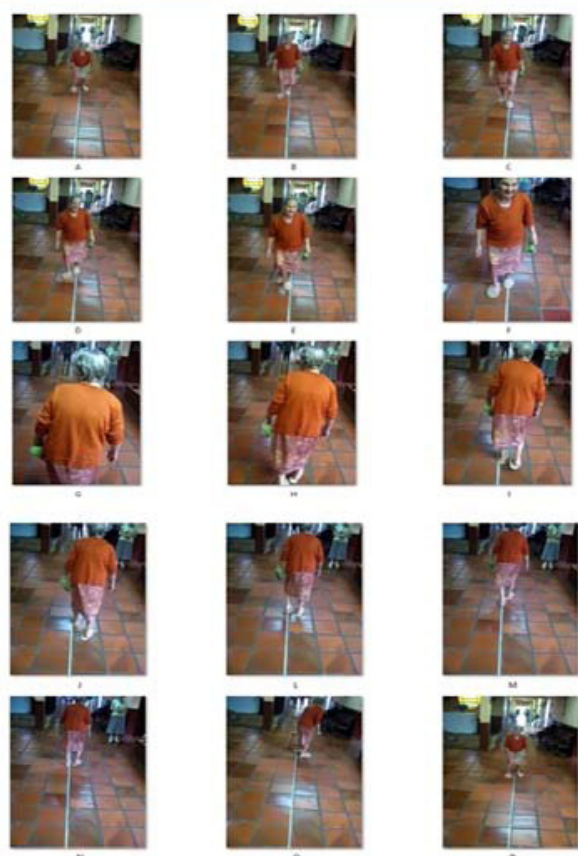

Fig. 1

TUG Test-Source: [Author] 
The risk of falls was assessed through the TUG Test [33,37], which assesses the basic functional mobility of the elderly, being conducted through the analysis of time and number of steps used by the elderly when getting up from the chair, walking 3 meters, returning and sitting back on the chair, and the more steps and time the elderly needed to complete the course, the higher the risk of falls. The test started by the command "go" and ended when the elderly sat back on the chair. The results of this test showed times below 10 seconds, indicating low risk of falls, while times between 11 to 20 seconds show interrmediate risk of falls, and times exceeding 20 seconds indicate high risk of falls (Fig.1).

To determine the handgrip strength, a hand dynamometer model Jamar ${ }^{\circledR}$ was used, which provides the result in kilogram-force (kgf). The protocol for conducting handgrip strength evaluations was in accordance with standards of the Brazilian Society of Hand and Upper Limb Therapists [1].

The analysis of films and timing was performed with the aid of a free program of video editing, which provides conditions for storage, editing and timing of events. A questionnaire was administered through interviews conducted individually, complemented by the analysis of records of internal files of the institution. The information collected is restricted to sociodemographic data and issues related to falls.

\subsection{Data analysis}

The data were processed through descriptive statistical analysis and ANOVA (two-way) followed by Tukey test, with the aid of the SPSS software for Windows, version 14.0.

\section{Results}

The results indicated a significant influence on body strength index on the risk of falls (Table 1).

Table 1

Influence of the Handgrip strength on the risk of falls in the last 12 months $-(p<0.05)$

\begin{tabular}{|c|c|c|}
\hline Percentage of falls & Handgrip strength & Risk of falls \\
\hline $32 \%$ & $24.32 \pm 11.22 \mathrm{kgf}$. & Low risk \\
\hline $40 \%$ & $23.82 \pm 10.18 \mathrm{kgf}$. & Intermediate risk \\
\hline $8 \%$ & $19.48 \pm 08.21 \mathrm{kgf}$. & High risk \\
\hline $20 \%$ & $18.13 \pm 07.33 \mathrm{Kgf}$. & High risk \\
\hline
\end{tabular}

The results showed that in the last 12 months, only $32 \%$ of seniors surveyed had no fall, $40 \%$ had one fall, $8 \%$ two falls and $20 \%$ had more than one fall.
The incidence of falls was higher in the month of July (30\%), followed by August (20\%), coinciding with the winter months in that region. There was a record of high-seriousness fall, as the older adult died from head injury. Thus, care for the elderly due to cold weather should be redoubled. As for the handgrip strength test results, it was found that among elderly evaluated, $32 \%$ who had no history of falls, the average strength found was $24.32 \mathrm{kgf}( \pm 11.22)$. Among those who had one fall, the average strength was $23.82 \mathrm{kgf}( \pm 10.18)$. For those who had two falls, the average strength was $19.48 \mathrm{kgf}( \pm 8.21)$, and for the others, with many records of falls, the average strength was $18.13 \mathrm{kgf}( \pm 7.33)$, (Table 1).

\section{Discussion}

With advancing age, human beings have changes in their functional capacity, and from the age of 60 years, there is a considerable decrease, especially in reducing the pace extent, weakness in the pelvic rotation and weaknesses in the movement of the arms with decreased scapular mobility $[4,13,25]$.

A postural change is also observed, since the spine and center of gravity from the age of 60 years undergo alterations that change the balance considerably, since changes in orthostatic posture in relation to age are manifested at the level of the sagittal plan, with significant increase in the thoracic kyphosis, decreased lordosis of the lumbar spine, posteriorization of the femoral joint, anteriorization of the trunk and increased knee flexion angle [16].

In addition to the orthostatic posture, the agerelated normal changes should also be considered, such as loss of bone mass (osteopenia) and loss of muscle mass (sarcopneia), loss of vision, which considerably influences the balance of older adults, affecting mainly the quadriceps muscles, especially the gluteus medius, which is the main muscle involved in walking $[8,12,21,30]$. Thus, buildings and products aimed at this population will contribute to a better quality life, since the loss of strength is normal at this stage, requiring additional work with health professionals, mainly physiotherapists, so that the strength levels of the population does not reach critical levels [38]. Thus, it is important to warn about the importance of accessibility, because only an accessible environment will be contributing to the prevention of accidents and improving the quality of life [18]. 
The following are among normal changes: physiological osteopenia, which is a progressive physiological loss of bone mass, which if not followed can progress to osteoporosis; and sarcopenia, which is the decrease in muscle mass $[11,26]$. Among the most affected muscles, quadriceps muscle stands out, and in some cases, there is a decrease of up to $50 \%$ of its strength, especially after the age of 70 years [12,39]. The level of force is significantly reduced with aging due to decreased synthesis of protein and muscle fibers, which can be worsened if the elderly is sedentary [7]. Therefore, it is important to warn that in aging, the level of force is an important variable, since over the years, its decline is imminent, becoming necessary to gain muscle strength in the upper and lower limbs $[7,43]$. Specific programs should be implemented to improve the muscle strength and accessibility for the elderly population $[7,18]$.

After the incidence of falls, it is important to make a proper ergonomic analysis, mainly by analyzing the location and time of the accident. The factors associated to the type of floor, shoes, carpets, slippery floors, functional condition and use of drugs should be reported in the analysis so that the correction is properly done $[20,38,47]$. Thus, in function of intrinsic and extrinsic factors that involve the physiology and the environment, it is necessary to search for an accessible environment, since according to the physiology of aging, ergonomic risks in any environment should be avoided [18]. It is not easy to make an accessible environment, especially when the environment was not built based on the accessibility principles, but it is necessary, especially when designed for people with poor mobility [24].

An architectural design for elderly subjects poorly constructed can provide serious consequences for this population, since architectonic barriers arising from this project will contribute to accidents and loss of functional mobility [17,24]. In this context, this building could be regarded as an unsuitable building, because it does not contribute to the quality of life of this population [29]. Thus, it is very important to know that during the aging process, the human being undergoes a significant physiological change, affecting mainly the locomotor system, vision, resistance and balance [23,27,42]. These authors warn that this population needs special attention, emphasizing that architectural barriers arising from a poorly designed building could be harmful to the health of users, who could be in danger of slipping and falls due to a reduction of balance and displacement of the center of gravity $[6,38]$.
For an effective prevention of falls in the elderly, several factors must be observed, both individually and collectively. Thus, the environment where these individuals interact, as well as their physical capacity, gender, age and use of drugs should be observed, so that favorable conditions for accessibility with comfort and safety can be provided [7].

It could be concluded that the strength levels are statistically different between subjects with risk of falls $(p<0.05)$, and that the lower the strength level, the higher the incidence of falls. Thus, it is important to stress that due to the loss of muscle strength, all ergonomic hazards and architectural barriers must be removed so that older adults can perform their tasks more easily, with comfort and safety.

\section{Reference}

[1] L.M. Abdalla and M.C.F. Brandão, Força de preensão palmar e digital. In: Sociedade Brasileira de Terapeutas da Mão e do Membro Superior. Manual: recomendações para avaliação do membro superior. $2^{\mathrm{a}}$ ed. São Paulo: SBTM, 2005.

[2] ABNT. Associação Brasileira de Normas Técnicas, NBR 9050, Acessibilidade, edificações, mobiliário e equipamentos urbanos, $2^{a}$ edição, Rio de Janeiro, 2004. Retrieved from: http://www.mpdft.gov.br/sicorde/NBR905031052004.pdf.

[3] A.G.S. Alice, et al., Identification of the risk of falls in elderly after stroke, Esc. Anna Nery 14(2010), 684-689.

[4] L.M.Alvares, R.C.Lima and R.A.Silva, Falls by elderly people living in long-term care institutions in Pelotas, Rio Grande do Sul State, Brazil, Cad. Saúde Pública 26(2010), 31-40.

[5] E.D.Alves Junior, F.P. Paula, The prevention of falls in the aspect of health promotion, Fi.t Perf. J., Rio de Janeiro, 7(2008), 123-129.

[6] O. Bretan, R.M. Pinheiro and J.E.Corrente, Balance and plantar cutaneous sensitivity functional assessment in communitydwelling elderly, Braz. j. otorhinolaryngol 76(2010), 219-224.

[7] R.R.Britto, L.Santiago and R.Eliza, Effect of exercise training in functional capacity of institucionalizes elderly, Textos Envelhecimento, UNATI, Rio de Janeiro 8(2005),262-268.

[8] M.P.Carvalho, E.L.T. Luckow, and F.V.Siqueira, Falls and associated factors in institutionalized elderly people in Pelotas (RS, Brazil), Revista Ciênc. saúde coletiva, 16(2011),29452952.

[9] R.C. Cassilhas, et al., The impact of resistance exercise on the cognitive function of the elderly,Medicine \& Science in Sports \& Exercise 39(2007), 1401-1407.

[10]E.P. César, O.V.Almeida, C.S.Pernambuco, R.G.S.Vale and E.H. Dantas, Aplicação de quatro testes do protocolo GDLAM. Rev Mineira Ed Física 12(2004), 18-37.

[11]G.J.Chapman, M.A.Hollands, Evidence that older adults fallers prioritise the planning of future stepping actions over the accurate execution of ongoing steps during complex locomotor tasks, Gait Posture 26(2007), 5967.

[12]H. Charchat-Fichman, P. Caramelli, K. Sameshima and R. Nitrini, Decline of cognitive capacity during aging, Rev. Bras. Psiquiatr. 27(2005), 79-82. 
[13]G. Christofoletti,M. Oliani, M., S.Gobbi and F.Stella, Effects of motor intervention in elderly patients with dementia: an analysis of randomized controlled trials, Topics in Geriatric and Rehabilitation 23(2007), 149-154.

[14]B.H. Connolly, Issues in aging in individuals with life long disabilities, Rev. Bras. Fisioter.10(2006),249-262.

[15] R. Davini R, C.V.Nunes, Neuromuscular changes decurrent of aging and the importante of physical exercise on maintenance strength in elderly people, Revista Bras.Fisioter.7( 2003), 201207.

[16] G.F.D.Duca,G.A. Nader, I.S. Santos, and P.C.Hallal, Hospitalization and risk factors among elderly individuals living in nursing homes, Cad. Saúde Pública 26(2010), 1403-1410.

[17] S.C.C.Fabricio, R.A.P.Rodrigues and M.L.Costa Junior, Falls among older adults seen at a São Paulo State public hospital: causes and consequences, Rev. Saúde Pública 38(2004), 9399.

[18]J.F. Fonseca and P.A.Rheingantz, The environment is suited? Pursuing the discussion, Revista Produção 19(2009), 502-513.

[19]L.M.P. Freitag, A.E.Aragão, P.C.Almeida, Acessibility and physical deficiency: identifying architectural: barriers in internal areas of hospitals in Sobral, Ceará, Revista Esc. Enferm., USP 41(2007), 581-588.

[20]Z.A.S.Gama, A.Gómez-Conesa, Factores de riesgo de caídas en ancianos, revisión sistemática, Ver. Saúde Pública 42(2008), 946-956.

[21]F.F.Gananca, et al., Elderly falls associated with benign paroxysmal positional vertigo, Braz. j. otorhinolaryngol. 76(2010),113-120.

[22] V.P. Gawryszewski, The importance of falls on the same level among the elderly in São Paulo state, Rev. Assoc. Med. Bras. 56(2010), 162-167.

[23] J,M. Gazzola, M.R. Perracini,M.M. Ganança and F.F, GanancaFunctional balance associated factors in the elderly with chronic vestibular disorder, Rev Bras Otorrinolaringol. 72(2006), 683-690.

[24]S. Gobbi, et al., Behavior and barriers: physical activity in institutionalized elderly, Revista Psic.Teor.Pesq. 24(2008), 451-458.

[25] S.E.Lamb, C. Mccabe, B.Clemens, L.P. Fried and J.M.Guralnik. The Optimal sequence and selection of screening test items to predict fall risk in older disabled women: The Women's Health and Aging Study, Journal of Gerontol. Med. Sci 63A(2008), 1082-1088.

[26] R.S. Lima and M.L.P.CAMPOS, Profile of the elderly trauma victims assisted at an Emergency Unit, Rev. esc. enferm. USP 45(2011), 659-664

[27] H.Lund, et al., A randomized controlled trial of aquatic and land-based exercise in patients with knee osteoarthritis. J Rehabil Med. 40(2008), 137-144.

[28]B.G.Macedo, et al., Parâmetros clínicos para identificar o medo de cair em idosos. Fisioterapia em Movimento, Curitiba 18(2005), pp.65-70

[29]T.R.Machado, C.J.Oliveira, F.B.C.Costa and T.L.Araujo, Evaluation of the risk of falls in the elderly, Rev. Eletr. Enferm. 11(2009), 32-38.

[30]A.C.C.Maciel and R.O. Guerra, Factors associated with alteration of mobility among elderly residents in the community, Revista Bras. de Fisioter. 9(2005), 17-23.

[31]C.P. Núbia, et al., Effectiveness of aquatic and non-aquatic lower limb muscle endurance training in the static and dynamic balance of elderly people, Rev. Bras. Fisioter, São Carlos 14(2010), 229-236.

[32]D.A. Paccola, et al. Prevalence of falls in women after menopause, Rev. Bras. Cresc. e Desenv. Hum. 21(2011), 146-155.
[33]R. Pedrosa and G. Holanda, Correlation between the walk, 2minute step and tug tests among hypertensive older women, Rev. Bras. Fisioter., São Carlos 13(2009), 252-256.

[34]L.S.M. Pereira, S.Bucksman, M.P.L. Perracini, K.M.L.Barreto and V.M.M.Leite, Quedas em idosos, projeto diretrizes, Revista AMRIGS 48(2004), 43-65.

[35]F.Pereira, T.Miguel and A. Fernandes, Factors, risks and consequences of falling in elderly long-term institutions, $\mathrm{Re}$ vista Transdisciplinar de Gerontologia, 4(2011), 32-42.

[36] M.R.Perracini, Challenges of prevention and management of falls in elderly, BIS, Bol. Inst. Saúde 47(2009), 45-48.

[37]D.Podsiadlo and Richardson S. The "Timed Up and Go": a test of basic functional mobility for frail elderly persons. J. Am. Geriatr. Soc. 39(1991), 142-148.

[38]J.R. Rebelatto, J.I. Calvo, J.R. Orejuela, and P.C.Portilho, Influence of a long-term physical activity program of hand muscle strenght and body flexibility among elderly women, Ver. Bras. Fisioter. 10(2006), 383-389.

[39] S.M. Resende, C.M. Rassi and F.P. Viana, Effects of hydrotherapy in balance and prevention of falls among elderly women, Ver. Bras. Fisioter. 12(2008), 57-63.

[40]A.P. Ribeiro, et al., The influence of falls on the quality of life of the aged, Ciência \&Saúde Coletiva 13(2008), 1265- 1273

[41]F.L.R.Rocha, M.H.P. Marziale, Prevention of hospitalized patient falls: a nursing care, revista Acta Paul. Enferm. 14(2001), 62-71.

[42] M.C. Santos and M.C. Andrade, Fall incidents related to risk factors in institutionalized elders, Rev Saúde Pública 29(2005), 5768.

[43]A. Silva, et al., Balance, Coordination and Agility of Older Individuals Submitted to Physical Resisted Exercises Practice, Rev Bras Med. Esporte 14(2008), 88-93.

[44]F.V.Siqueira, L.A. Facchini and R.X. Piccini, Prevalence of falls and associated factors in the elderly, Rev. Saúde Pública 41(2007), 749-756.

[45] A.V.Soares, F.M. Matos, L.M.Laus and S. Susuki, Comparative study about propensity for falling in institutionalized and non-institutionalized elderly people regarding their functional mobility level, Revista. Bras. Fisioter. 4(2003), 12-15.

[46]D.C. Teixeira, I.L. Oliveira and R.C. Dias, Demographic, clinical and functional profile of institutionalized elderly with history of falls, Rev. Fisioter. Mov.9(2006), 101-108.

[47] N.Wada, M.Sohmiya, T.Shimizu, K. Kamoto and K. Shirakura, Clinical analysis of risk factors for falls in home-living stroke patients using functional evaluation tools, Arch. Phys. Med. Rehab.88(2007)1601-1605. 